\title{
Mercury isotopic fractionation in latosol profile developed from strongly weathered basalt
}

\author{
XIN GAO $^{1}$, YUANMING ZHANG ${ }^{2}$, FANG HUANG ${ }^{3}$, JIUBIN \\ $\mathrm{CHEN}^{2}$ AND WANG ZHENG ${ }^{2}$ \\ ${ }^{1}$ Tianjin Universerty \\ ${ }^{2}$ Tianjin University \\ ${ }^{3}$ CAS Key Laboratory of Crust-Mantle Materials and \\ Environments, School of Earth and Space Sciences, University \\ of Science and Technology of China \\ Presenting Author: natie2017@163.com
}

Weathering is a key process transferring material from continents to the hydrosphere, and plays a critical role in the cycling of trace elements. Mercury $(\mathrm{Hg})$ is a toxic heavy metal and well-known global pollutant. Soil is the largest reservoir of $\mathrm{Hg}$ on Earth surface, and thus the behavior of $\mathrm{Hg}$ during soil weathering significantly affects how $\mathrm{Hg}$ transports from terrestrial to aquatic environment and biota. However, the transport and fate of $\mathrm{Hg}$ during soil weathering are rarely studied. The fractionation of $\mathrm{Hg}$ stable isotopes has been widely used to trace $\mathrm{Hg}$ cycling. Here we measured $\mathrm{Hg}$ concentration and isotope ratios in a latosol profile in Zhanjiang, Guangdong Province, South China, formed through intense weathering of basalt, in order to understand how $\mathrm{Hg}$ isotopes fractionate during weathering. All soil samples showed significantly negative $\delta^{202} \mathrm{Hg}\left(-2.97 \%\right.$ o to $-2.54 \%$ ) and $\Delta^{199} \mathrm{Hg}(-0.68 \%$ o to $-0.43 \%$ ), which are dramatically different from those of the bedrock $\left(\delta^{202} \mathrm{Hg}=-7.30 \%, \Delta^{199} \mathrm{Hg}=-0.05 \%\right)$, suggesting that throughout the profile $\mathrm{Hg}$ was dominantly from atmospheric deposition rather than from bedrock. The $\mathrm{Hg}$ enrichment and isotope compositions both show distinct patterns below and above $\sim 300 \mathrm{~cm}$. There was significant leaching loss of $\mathrm{Hg}$ below $\sim 300 \mathrm{~cm}$, but almost no variation in $\delta^{202} \mathrm{Hg}$. This is likely because $\mathrm{Hg}$ was absorbed by $\mathrm{Fe}$ hydro(oxide) and clay colloid, which were completely weathered and migrated, resulting in little isotope fractionation. In contrast, there was a slight increase in $\mathrm{Hg}$ enrichment above $300 \mathrm{~cm}$, suggesting that the atmospheric input outweighs the leaching loss in the upper section. The soils above $300 \mathrm{~cm}$ also show much more negative $\Delta^{199} \mathrm{Hg}$ than the average $\Delta^{199} \mathrm{Hg}$ of atmospheric $\mathrm{Hg}(0)$, the source of $\mathrm{Hg}$ in our profile, and a downward positive shift of $\Delta^{199} \mathrm{Hg}$. We suggest that $\mathrm{Hg}$ deposited from the atmosphere has undergone photoreduction on the surface, which would produce negative $\Delta^{199} \mathrm{Hg}$ when $\mathrm{Hg}$ is complexed by thiols in organic matter, and was subsequently leached downward. Overall, our results suggest that weathering is unlikely to cause significant fractionation of $\mathrm{Hg}$ isotopes, and the $\mathrm{Hg}$ isotope compositions in soils are primarily controlled by atmospheric deposition and photoreduction on the surface layer. 